\title{
O LUGAR SOCIAL DA MULHER NA CRIMINALIDADE: UM OLHAR PANORÂMICO SOBRE A AMÉRICA LATINA
}

\author{
Miquelly Barbosa da Silva ${ }^{1}$ \\ Rebecca Lemos Igreja ${ }^{2}$
}

\section{RESUMO}

O presente artigo expõe um breve panorama sobre o encarceramento de mulheres na América Latina, enfatizando o contexto dos delitos de drogas e debatendo rupturas e continuidades dos lugares sociais da mulher dentro de uma construção histórica. Propõe-se identificar e caracterizar as identidades socioculturais da mulher envolvida no mundo da criminalidade. A pesquisa aborda o acesso à Justiça através de um estudo sobre o papel da "mulher" no mundo do tráfico de drogas, em perspectiva centrada em seu "lugar social" no mundo do crime, em uma análise comparada entre países da América Latina, em especial dados de Brasil e México.

PALAVRAS-CHAVE: Mulher; tráfico de drogas; América Latina; Lugar Social; Acesso à Justiça

\section{THE SOCIAL PLACE OF WOMEN IN CRIMINALITY: A PANORAMIC VIEW ON LATIN AMERICA}

\begin{abstract}
This article presents a brief overview of the imprisonment of women in Latin America, emphasizing the context of drug offenses and discussing ruptures and continuities of women 's social places within a historical construction. It is proposed to identify and characterize the sociocultural identities of women involved in the world of crime. The research addresses access to justice through a study on the role of "women" in the world of drug trafficking, in a perspective centered on their "social place" in the world of crime, in a comparative analysis among Latin American countries, in special data from Brazil and Mexico.
\end{abstract}

KEYWORDS: Woman; drug trafficking; Latin America; Social Place; Access to justice

\footnotetext{
${ }^{1}$ Mestranda em Ciência Política (Unieuro). Integra o Grupo de Estudos Comparados México, Caribe, América Central e Brasil (MeCACB), vinculado ao Departamento de Estudos Latino-Americanos (ELA) da Universidade de Brasília (UnB). Desenvolve atividades junto à equipe do periódico Abya-yala: Revista sobre Acesso à Justiça e Direitos nas Américas, no âmbito das atividades do Laboratório de Estudos Interdisciplinares sobre acesso à Justiça e direitos nas Américas - LEIJUS. É advogada (OABDF) e defensora pública no Centro de Assistência Judiciária de Novo Gama/GO. Professora de Direito no UNIDESC.

${ }^{2}$ Antropóloga, professora adjunta e coordenadora da Pós-Graduação do Departamento de Estudos LatinoAmericanos/UnB. É coordenadora do Laboratório de Estudos Interdisciplinares sobre Acesso à Justiça e Direitos nas Américas - LEIJUS/UnB e coordenadora do Grupo de Estudos Comparados México, Caribe, América Central e Brasil (MeCACB)
} 


\section{INTRODUÇÃO}

A criminalidade vem ocupando centralidade nas políticas públicas da América Latina e Caribe (ADORNO, 2008) e, assim, tem despertado o interesse cada vez maior das pesquisas em Ciências Sociais (RATTON, GALVÃO e ANDRADE, 2011). Nessa linha, vem avançando os estudos que procuram decifrar as percepções, os fatos e acontecimentos, o impacto sobre a justiça (IGREJA, 2012), as formas e significados da violência para os distintos grupos sociais (ADORNO e CARDIA, 2002).

Além da política e da academia, a criminalidade repercute sobre as sociedades latino-americanas (GÓMEZ, 2013), colocando em evidência o espaço do tráfico de drogas, sua rede de violência, comércio e lógicas (MISSE, 2003). Um elemento que tem se destacado no tráfico de drogas é a presença cada vez maior de mulheres, muitas vezes ocupando tarefas subalternas, como a função de "mula ou vapor", mas, também em postos de gerência e domínio nas bocas de fumo (HELPES, 2014, p. 15).

Desde os anos 1970 é crescente a atividade de traficância, com impactos progressivos na economia, política e geopolítica do continente. Na América Latina, concentram-se a produção, processamento e exportação de coca e cocaína. Desde os anos 1990, outras substâncias, como a heroína, tornaram-se "mercadorias" de grande repercussão financeira e sociocultural (PEREIRA, 2010). Assim, diferentes países na América Latina, dentre eles, Brasil e México, têm proposto reflexões e diálogos institucionais com a finalidade de ampliar o acesso à justiça para as populações de baixa renda, conectando o debate com as políticas públicas de encarceramento de mulheres envolvidas com crimes (IGREJA, 2012, p. 20).

Diante desse cenário instigante, a presente pesquisa aborda o acesso à Justiça nas Américas, por meio de um estudo sobre o papel da "mulher" no mundo do tráfico de drogas, em uma perspectiva que se centra em seu "lugar social" (GROSFOGUEL, 2008) no mundo do crime, suas nuances, rupturas e continuidades. O que aqui se propõe é uma análise comparada sobre o tema entre países de América Latina, enfatizando dados do Brasil e México ${ }^{3}$.

A opção pelo estudo do lugar social do gênero feminino, enquanto objeto de pesquisa, leva em conta que, dentro dos estudos que versam sobre a criminalidade, há

\footnotetext{
${ }^{3}$ Os levantamentos estatísticos utilizados neste trabalho, em especial os do INPEC (2014) e do INDEPAZ (2015), tratam de amostragens comparativas e de perfis nacionais, não sendo o objetivo deste artigo trazer recortes internos aos países, mas ater-se a uma leitura panorâmica de suas realidades carcerárias.
} 
uma predominância de trabalhos voltados ao sexo masculino (atores e vítimas). Dessa forma, a criminalidade feminina é tema negligenciado por grande parte dos estudiosos no Brasil e no exterior, ocupando papel secundário na maior parte das pesquisas (RATTON, GALVÃO e ANDRADE, 2011; HELPES, 2014, p. 15). Por outro lado, parte significativa da bibliografia especializada (ADORNO, 2008; MACHADO, 2014; SCHRITZMEYER, 1999) destaca que, nesses crimes, a mulher ocupa posições peculiares na composição social das atividades. Exemplo disso são as mulheres que prestam serviços de transporte ou de pequeno comércio ilícito, muitas vezes pela necessidade de sustentar suas próprias famílias (MENDES, 2016). Tais dados demonstram que existe uma realidade específica a ser compreendida como fenômeno social no âmbito do acesso à justiça e direitos na América Latina.

Assim, portanto, propõe-se nesse texto identificar e caracterizar as identidades socioculturais da mulher envolvida no mundo da criminalidade, em uma perspectiva comparada e com base em informações colhidas em base de dados pública e em bibliografias. Esse artigo tem como pano de fundo metodológico a pesquisa bibliográfica, levando em conta um comparativo da realidade carcerária feminina entre países da América Latina. Por fim, o presente trabalho se inicia expondo um breve panorama sobre o encarceramento de mulheres na América Latina, enfatizando o contexto dos delitos de drogas (tópico 1). Em seguida, debatem-se as rupturas e continuidades dos lugares sociais da mulher dentro da construção histórica daqueles que foram considerados domináveis e exploráveis, desde os processos de exploração colonial dos povos e das terras (tópico 2). Vale ressaltar, este artigo não pretende fechar questão sobre um problema de pesquisa, nem apresenta conclusões definitivas, estando fundamentado em um primeiro levantamento de dados e em algumas reflexões realizadas no âmbito de um projeto de pesquisa sobre o tema.

\section{PERFIL DO ENCARCERAMENTO DE MULHERES NA AMÉRICA LATINA}

A população carcerária feminina na América Latina aumentou, em termos gerais, $51,6 \%$ de 2000 a 2015. Nesse mesmo período, houve um acréscimo de $20 \%$ no caso dos homens e, embora o número de homens privados da liberdade seja maior, os 
níveis de encarceramento de mulheres estão crescendo a uma taxa mais rápida. Esses números podem ser dimensionados numa perspectiva comparada da América Latina:

Tabela 1- América Latina: percentuais de mulheres no perfil geral da massa carcerária

\begin{tabular}{|c|c|c|c|c|c|}
\hline & $\begin{array}{l}\text { Población total de } \\
\text { mujeres en prisión }\end{array}$ & $\begin{array}{l}\text { \% Mujeres en } \\
\text { relación al total } \\
\text { de presos }\end{array}$ & $\begin{array}{c}\text { Tasa de mujeres } \\
\text { encarceladas en } \\
100.000 \text { hab. } \\
\text { (población nacional) } \\
\text { - ICPS } \\
\end{array}$ & $\begin{array}{l}\text { Aumento de la tasa de } \\
\text { encarcelamiento femenino } \\
\text { por cada } 100.000 \text { mujeres - } \\
\text { ICPS }\end{array}$ & $\begin{array}{l}\text { Aumento de la tasa de } \\
\text { encarcelamiento por } \\
\text { cada } 100.000 \text { habitantes - } \\
\text { ICPS }\end{array}$ \\
\hline ARG & $\begin{array}{l}2.839 \\
(2013)\end{array}$ & $\begin{array}{l}4 \cdot 42 \% \\
(2013)\end{array}$ & $\begin{array}{c}6.8 \\
(2013)\end{array}$ & $\begin{array}{c}6.4-6.8 \\
(2003 / 2013)\end{array}$ & $\begin{array}{c}152-161 \\
(2002 / 2012)\end{array}$ \\
\hline BOL & $\begin{array}{l}1.195 \\
(2015)\end{array}$ & $\begin{array}{l}8.66 \% \\
(2015)\end{array}$ & $\begin{array}{c}12.9 \\
(2011)\end{array}$ & $\begin{array}{c}16.2-12.9 \\
(2000 / 2011)\end{array}$ & $\begin{array}{c}95-135 \\
(2000 / 2012)\end{array}$ \\
\hline BRA & $\begin{array}{l}35.218 \\
(2013)\end{array}$ & $\begin{array}{l}6.3 \% \\
(2013)\end{array}$ & $\begin{array}{c}17 \cdot 5 \\
(2013)\end{array}$ & $\begin{array}{c}5.8-17.5 \\
(2000 / 2013)\end{array}$ & $\begin{array}{c}133-300.96 \\
(2000 / 2013)\end{array}$ \\
\hline COL & $\begin{array}{c}8.379 \\
(2014)\end{array}$ & $\begin{array}{c}7 \% \\
(2015)\end{array}$ & $\begin{array}{c}16.5 \\
(2015)\end{array}$ & $\begin{array}{c}7.8-16.5 \\
(2000 / 2015)\end{array}$ & $\begin{array}{c}128-231 \\
(2000 / 2014)\end{array}$ \\
\hline CR & $\begin{array}{l}2.346 \\
(2014)\end{array}$ & $\begin{array}{l}7.15 \% \\
(2014)\end{array}$ & $\begin{array}{c}20.4 \\
(2014)\end{array}$ & $\begin{array}{c}10.8-20.4 \\
(2003 / 2014)\end{array}$ & $\begin{array}{c}193-303 \\
(2000 / 2012)\end{array}$ \\
\hline ECU & $\begin{array}{l}1.636 \\
(2015)\end{array}$ & $\begin{array}{c}6.7 \% \\
(2015)\end{array}$ & $\begin{array}{c}12.5 \\
(2014)\end{array}$ & $\begin{array}{c}5.2-12.5 \\
(2002 / 2014)\end{array}$ & $\begin{array}{c}70-165 \\
(1989 / 2014)\end{array}$ \\
\hline EEUU & $\begin{array}{c}205.400 \\
(2013)\end{array}$ & $\begin{array}{l}9.3 \% \\
(2013)\end{array}$ & $\begin{array}{c}64.6 \\
(2013)\end{array}$ & $\begin{array}{l}55.6-64.6 \\
(2001 / 2013)\end{array}$ & $\begin{array}{c}683-731 \\
(2000 / 2010)\end{array}$ \\
\hline MEX & $\begin{array}{l}13.395 \\
(2015) \\
\end{array}$ & $\begin{array}{c}5.2 \% \\
(2015)\end{array}$ & $\begin{array}{c}21.6 \\
(2015)\end{array}$ & $\begin{array}{c}7.1-21.6 \\
(2001 / 2015)\end{array}$ & $\begin{array}{c}156-212 \\
(2000 / 2015)\end{array}$ \\
\hline PER & $\begin{array}{l}4.396 \\
(2015)\end{array}$ & $\begin{array}{l}6.0 \% \\
(2015)\end{array}$ & $\begin{array}{c}14.1 \\
(2015)\end{array}$ & $\begin{array}{c}7.8-14.1 \\
(2001 / 2015)\end{array}$ & $\begin{array}{c}107-193 \\
(2000 / 2012)\end{array}$ \\
\hline URU & $\begin{array}{c}645 \\
(2013) \\
\end{array}$ & $\begin{array}{c}6.6 \% \\
(2013) \\
\end{array}$ & $\begin{array}{c}17 \cdot 5 \\
(2014) \\
\end{array}$ & $\begin{array}{c}7.3-17.5 \\
(1999 / 2014)\end{array}$ & $\begin{array}{l}209-278.4 \\
(2003 / 2012) \\
\end{array}$ \\
\hline VEN & $\begin{array}{l}2.942 \\
(2014)\end{array}$ & $\begin{array}{c}5.7 \% \\
(2014)\end{array}$ & $\begin{array}{c}9 \cdot 5 \\
(2014)\end{array}$ & $\begin{array}{c}3.7-9.5 \\
(2001 / 2014)\end{array}$ & $\begin{array}{c}5^{8-150} \\
(2000 / 2012)\end{array}$ \\
\hline
\end{tabular}

Fonte: GIACOMELLO, 2013, p. 02.

É importante notar que o Brasil possuía 35.218 mulheres encarceradas em 2013, equivalente a 6,3\% do universo total de apenados. O México possuía 13.395 mulheres encarceradas em 2015, o que representa 5,2\% da população carcerária mexicana. Embora o número absoluto de cada país seja diferente, Brasil $(6,3 \%)$ e México $(5,2 \%)$ possuem uma proporção relativamente próxima de mulheres encarceradas. Além disso, ambos os países retratam a forte tendência latino-americana de crescimento das taxas de mulheres encarceradas. O Brasil saltou de 5,8 (em 2013) para 17,5 (em 2015) e o México subiu de 7.1 (em 2001) para 21,6 (em 2015). 
Outro ponto importante a se destacar nesse universo é que, de forma geral, países como Argentina, Brasil, Costa Rica e Peru possuem mais de $60 \%$ da população carcerária feminina privada de liberdade por delitos relacionados com drogas. Esse perfil vem sofrendo um aumento significativo, chegando ao incremento de $271 \%$ na Argentina (de 1989 a 2008) e de 290\% no Brasil (de 2005 a 2013) (SAAVEDRA et al, 2014; GIACOMELLO, 2013). Para melhor visualização da criminalidade relacionada aos delitos de drogas e às mulheres, pode-se sintetizar:

Tabela 2 - Países da América Latina e os aumentos percentuais de mulheres encarceradas.

\begin{tabular}{|c|c|c|}
\hline Pais & $\begin{array}{l}\text { Número de mulheres encarceradas } \\
\text { por crimes relacionados a drogas }\end{array}$ & $\begin{array}{l}\text { Porcentagem de mulheres encarceradas } \\
\text { por crimes relacionados a drogas }\end{array}$ \\
\hline \multirow[t]{2}{*}{ Argentina } & 790 & $65 \%$ \\
\hline & Estatística das Prisões Federais, 2013 & Dezembro de 2012 \\
\hline \multirow[t]{2}{*}{ Brasil } & 16.489 & $60,63 \%$ \\
\hline & Junho de 2013 & Junho de 2013 \\
\hline \multirow[t]{2}{*}{ Colômbia } & $\mathbf{3 . 8 3 0}$ & $45 \%$ \\
\hline & 2014 & 2014 \\
\hline \multirow[t]{2}{*}{ Costa Rica } & 944 & $75,46 \%$ \\
\hline & Dezembro de 2011 & Dezembro de 2011 \\
\hline \multirow[t]{2}{*}{ Chile } & 1.889 & $57,20 \%$ \\
\hline & Baseado na população de abril de 2015 & Baseado na população de abril de 2015 \\
\hline \multirow[t]{2}{*}{ Equador } & 709 & $43 \%$ \\
\hline & 2015 & 2015 \\
\hline \multirow[t]{2}{*}{ México } & $\begin{array}{l}\text { Federal } 528 \\
\text { Local } 1.547\end{array}$ & $\begin{array}{r}44,80 \% \\
14,20 \% \\
\end{array}$ \\
\hline & $2014 / 2013$ & Agosto 2014/Maio 2013 \\
\hline \multirow[t]{2}{*}{ Peru } & 2.679 & $60,60 \%$ \\
\hline & 2014 & 2014 \\
\hline \multirow[t]{2}{*}{ Uruguai } & 126 & $29,50 \%$ \\
\hline & 2014 & 2014 \\
\hline
\end{tabular}

Fonte: AMADOR et al, 2016, p. 10.

Portanto, no cenário latino-americano, como um todo, a mulher vem sendo encarcerada "a um ritmo alarmante e o aumento do encarceramento supera, juntamente com o da Ásia, o de qualquer outra região do mundo" (AMADOR, 2016, p. 09; WALMSLEY, 2015, pp. 02/13).

Assim, a assertividade desses números nos desafiam a compreender outras dimensões sociais e culturais da realidade feminina que leva e permeia o cárcere. Há, nesse lugar social nuances importantes, como um perfil sociodemográfico similar na 
América Latina. Isto é, as mulheres latino-americanas encarceradas por delitos de drogas são, predominantemente: jovens, pobres, mães solteiras e líderes de seus lares. Além disso, possuem baixa escolaridade, cuidam diretamente de seus familiares e pertencem a minorias étnicas, tais como negras e indígenas (KENSY et al, 2012; GIACOMELLO, 2013; PIERIS, 2014; SAAVEDRA et al, 2014; AMADOR et al, 2016), compondo o rol de categorias sociais privadas não apenas de liberdade, mas de acesso à justiça, identidade social e terras.

En la mayoría de los países de la región, con la excepción de Ecuador y Costa Rica, que recientemente cambiaron sus leyes de drogas, la legislación no hace la diferencia entre grados de participación e involucramiento de las mujeres en el delito, y ellas reciben condenas muy altas (METAAL Y YOUNGERS, 2011). Al reconocer esta cuestión de género, Costa Rica ha aprobado una ley para reducir penas en los casos de mujeres que ingresen con drogas a los penales, reconociendo que muchas de ellas viven en condiciones de vulnerabilidad, en gran parte asociadas al género. Otro ejemplo sería Bolivia, que recientemente aprobó un Decreto Supremo (DS 2437) que contempla con indulto a mujeres embarazadas con más de 24 semanas de gestación (GIACOMELLO, 2013, p. 05).

Apesar desses avanços pontuais, as realidades de Brasil e México reforçam as relações entre criminalidade e exclusão social feminina. Cerca de 55\% das mulheres brasileiras encarceradas (por crimes relacionados a drogas) são negras. No México, a maior parte dessas mulheres são indígenas e 43\% delas estão encarceradas por delitos ligados a drogas (HERNÁNDEZ, 2011, pp. 70/71). Para alguns pesquisadores (AMADOR, 2016; PIERIS, 2014; INPEC, 2014) esses números são influenciados fortemente por leis de drogas de caráter meramente punitivas e pela imposição de penas desproporcionais que "castiga a los más pobres y débiles em general, pero afecta de manera desproporcional a las mujeres en situación de exclusión social y/o de vulnerabilidade" (GIACOMELLO, 2013, p. 03).

\section{LUGARES SOCIAIS DA MULHER ENCARCERADA NA AMÉRICA LATINA: RUPTURAS E CONTINUIDADES}

A ideia de lugares sociais na América Latina está intimamente relacionada à construção histórica daqueles que foram considerados domináveis e exploráveis, desde os processos de exploração colonial dos povos e das terras. É importante distinguir "lugar epistêmico" e "lugar social". Para Grosfoguel o fato de alguém "se situar 
socialmente no lado oprimido das relações de poder não significa automaticamente que pense epistemicamente a partir de um lugar epistêmico subalterno". O "êxito do sistema-mundo colonial/moderno reside em levar os sujeitos socialmente situados no lado oprimido da diferença colonial a pensar epistemicamente como aqueles que se encontram em posições dominantes” (GROSFOGUEL, 2008, p. 119).

Nesse sentido, o lugar social da mulher é perpassado por "várias hierarquias globais enredadas e coexistentes no espaço e no tempo". É uma composição que remonta às origens coloniais, quando uma hierarquia étnico-racial global passou a privilegiar os povos europeus relativamente aos não-europeus (QUIJANO, 1993, 2000), em consonância com uma hierarquia global, que privilegiou os homens relativamente às mulheres (SPIVAK, 1988; ENLOE, 1990; GROSFOGUEL, 2008, p. 122). Nesse sentido:

De acordo com o mito do estado de natureza e da cadeia do processo civilizatório que culmina na civilização européia, algumas raças -negros (ou africanos), índios, oliváceos, amarelos (ou asiáticos) e nessa seqüência- estão mais próximas da "natureza" que os brancos. [...]. Daí em diante, o lugar das mulheres, muito em especial o das mulheres das raças inferiores, ficou estereotipado junto com o resto dos corpos, e quanto mais inferiores fossem suas raças, mais perto da natureza ou diretamente, como no caso das escravas negras, dentro da natureza. É provável, ainda que a questão fique por indagar, que a idéia de gênero se tenha elaborado depois do novo e radical dualismo como parte da perspectiva cognitiva eurocentrista (QUIJANO, 2005, p. 129).

Assim, o lugar social deve ser contextualizado como parte de um todo fundado em agentes e dinâmicas históricas que "inferiorizam seres humanos (colonialidade do ser), dominam o mundo natural (colonialidade da natureza), constroem hierarquias de gênero (colonialidade do gênero) e hierarquizam seres e lugares a partir de uma matriz de poder global com o objetivo de melhor explorá-los para a acumulação de capital" (RESTREPO e ROJAS, 2010, p. 37/38).

Dentro desse contexto histórico mais amplo, é que se deve observar as mulheres inseridas na criminalidade. Elas buscam as drogas não apenas para o consumo, mas participam de delitos ligados a sua produção, distribuição, fornecimento e venda. Essas condutas, porém, se relacionam à exclusão social, à pobreza e à violência de gênero, fazendo com que a maioria das mulheres não tenham, de fato, a liberdade de decidir autonomamente sobre suas vidas pessoais e profissionais. Isso decorre de uma 
desigualdade social histórica em que a maioria possui pouca ou nenhuma instrução educacional e, ainda assim, são responsáveis pelo sustento de seus dependentes (crianças, jovens, pessoas idosas ou deficientes). É o caso da Colômbia, onde $76 \%$ das presidiárias são oriundas de uma condição anterior de pobreza, marcada por graves restrições ao ensino básico e ao mercado formal (AMADOR, 2016, p. 09; PIERIS, 2014, p. 02; INPEC, 2014).

Outro dado social importante sobre as mulheres encarceradas por delitos de drogas na América Latina é que, na grande maioria, são "mães solteiras”. Situações das mais extremas é o da Costa Rica que, em 2012, apresentava o exorbitante número de 95\% de mulheres presas (por introduzirem drogas em penitenciárias) como mães solteiras. Essas mulheres eram as únicas responsáveis pela mantença de seus filhos (AMADOR, 2016, p. 09; COSTA RICA, 2012, p. 04) e sua ausência não é um dado apenas para a queda da renda da família. Seu encarceramento impacta toda a vivência afetiva e cultural do núcleo familiar e comunitário, gerando prejuízos que se somam a fatores regionais e retroalimentam outras formas de criminalidade:

Desde un enfoque de género, los efectos colaterales del encarcelamiento son evidentes. Las consecuencias del uso de las cárceles pueden ser vistas no sólo en la forma em que las vidas de estas mujeres son afectadas, sino también en los efectos sobre su familia, hijos y dependientes, desprotegidos social y económicamente. En Colombia, del total de mujeres que ingresaron a las cárceles por delitos de drogas entre 2010 y 2014, 93\% tenían hijos, mientras que para el caso de los hombres los que tenían hijos representaban el $76 \%$ del total. En un estudio realizado por la Defensa Pública de Costa Rica, se demuestra que de las 120 mujeres condenadas por intento de introducción de drogas a un centro penal (15\% del total), un $50 \%$ tiene 3 o más hijos a su cargo (Muñoz, 2012). Esto significa que el encarcelamiento de mujeres por delitos de drogas tiene un impacto mayor sobre la destrucción de lazos familiares y genera mayores afectaciones sobre el interés superior de niños y niñas, sin desconocer los impactos sobre las propias mujeres (más allá de su condición de madres) (GIACOMELLO, 2013, p. 04)

Portanto, o envolvimento da mulher com o crime traz a reboque um lugar social marcado pela exclusão social, pobreza e violência de gênero. Assim, a criminalidade representa uma alternativa não apenas de sustento socioeconômico e ganho de renda, mas também de conquista, respeito e empoderamento sociocultural em suas família e comunidades (SAAVEDRA et al, 2014; GIACOMELLO, 2013). Diante 
dessa complexidade, as explicações dadas pelas mulheres encarceradas por delitos de drogas para seus atos são muito diversas. É necessário pesquisar melhor essas narrativas ${ }^{4}$, como formas de compreender o lugar social e cultural da mulher no mundo do crime, em especial na América Latina.

Embora haja mulheres que indicam terem se envolvido por vontade própria e estarem conscientes dos riscos associados com o negócio, aparece com frequência a coerção do parceiro ou de um membro da família, facilitada pela construção de vínculos sentimentais decorrentes de estereótipos de gênero e de relações desiguais de poder entre homens e mulheres. Há mulheres encarceradas que afirmam terem sido enganadas e não terem conhecimento do que estavam fazendo, ao passo que outras manifestam não estarem conscientes de todos os riscos que corriam, além das que, simplesmente, afirmam ter acreditado no parceiro que lhes dizia: "tudo vai dar certo" (AMADOR, 2016, p. 09).

No que tange às peculiaridades de lugar social, a mulher no tráfico de drogas na América Latina é, na maior parte das vezes, envolvida em tarefas de pouca importância, mas de alto risco (AMADOR, 2016, p. 11; METAAL e YOUNGERS, 2010). Assim, "las mujeres encarceladas en América Latina por delitos de drogas lo están principalmente por delitos no violentos de micro-tráfico o transporte de drogas" (GIACOMELLO, 2013, p. 01).

Antes da atuação repressiva do Estado, porém, as mulheres no mundo do crime crescem em ambientes propícios para o envolvimento em atividades ilícitas e não dispõem de meios ou de capital social para gerar alternativas de vida. Em muitos casos foram vítimas de conflitos urbanos e rurais, abuso sexual, exploração sexual comercial, etc., sem terem acesso a serviços públicos básicos. Uma vez terminada a pena e postas em liberdade, seus antecedentes penais prejudicam a possibilidade de encontrarem emprego formal, o que perpetua o círculo vicioso de exclusão social e encarceramento no qual estão inseridas (AMADOR, 2016, p. 11; KENSY et al, 2012, p. 11).

Essa perspectiva de violências e desigualdades continua repercutindo dentro do cárcere. Alguns grupos de mulheres são ainda mais propensos à discriminação na aplicação das leis de drogas: indígenas, afrodescendentes, pessoas de orientação sexual, identidade ou expressão de gênero diversas estão nesse grupo de maior exposição à violência no interior dos presídios (lesões físicas e psicológicas, privação de alimentos e

\footnotetext{
${ }^{4}$ Essa análise está em andamento no projeto de mestrado da co-autora Miquelly Barbosa da Silva.
} 
higiene, restrição de medicamentos, negação de identidades e subjetividades). Alguns estudos no Canadá e Estados Unidos mostram que as mulheres pertencentes a povos indígenas e minorias étnicas têm mais probabilidades de serem detidas, processadas e condenadas. Por exemplo, nos Estados Unidos, as mulheres afro-americanas têm sete vezes mais probabilidades de serem encarceradas do que as mulheres brancas (KENSY et al, 2012, p. 11). No Brasil, a prática demonstra que 55\% das mulheres encarceradas são afrodescendentes (AMADOR, 2016, p. 11; BOITEUX, CHERNICHARO e BARRETO, 2015, p. 02).

Por outro lado, as vivências culturais e sociais ocupam destaque nesse debate, como ponto de contato entre as tradições das comunidades e as atividades de traficância ilegal, pois:

Não existe manual de antropologia ou de sociologia histórica sobre o uso de drogas que não comece lembrando que o consumo de produtos psicoativos é um fenômeno antigo e universal. Da mastigação da folha de coca, nos Andes, passando pela ingestão de peiote (certo tipo de alucinógeno), praticada pelo povo huichol, no México (CARDINAL, 1998), até o consumo de álcool fermentado no Sudeste asiático, o uso dessas substâncias com finalidades medicinais, artísticas, espirituais, religiosas, entre outras, foi por muito tempo, e continua a ser, uma prática comum (BERGERON, 2012, p. 19-20).

Portanto, mais do que uma definição a partir dos aspectos biológicos causados pelas substâncias, o conceito "droga" é social e cultural, um produto de lutas simbólicas e científicas, políticas e sociais. O termo se tornou aquilo que é "socialmente definido como tal pela sociedade e que é juridicamente classificado como tal pelo direito" (BERGERON, 2012, p. 17, HELPES, 2014, p. 66).

Nesse sentido, o lugar social da mulher sofre implicações particulares no caso latino-americano. Há que se considerar, por exemplo, o contingente de mulheres indígenas e camponesas que dependem economicamente da produção de cultivos da maconha, coca, papoula, bem como da subsistência por lavouras de usos ancestrais na América Latina. Os encarceramentos orientados apenas por argumentos legais, representam a eliminação da principal fonte de renda dessas mulheres, que também são atingidas por campanhas de erradicação forçada das culturas tradicionais, pela desterritorialização de suas comunidades, a estrangeirização e a commoditização de culturas e glebas (CASTRO e IGREJA, 2017), a partir do que o encarceramento é apenas uma das violências visíveis. $O$ conjunto da obra compõe, assim, o 
aprofundamento de históricos processos de exclusão social que "as leva ainda mais para a pobreza, promove deslocamentos internos e desencadeia uma série de violações de direitos humanos, reforçando sua situação prévia de vulnerabilidade e discriminação" (AMADOR, 2016, p. 11; INDEPAZ, 2015).

No caso mais específico de alguns países, como o Brasil, as atividades que envolvem o cultivo, produção e distribuição de drogas colocam a maioria das mulheres latino-americanas no nível mais baixo da cadeia do crime organizado, seja como pequenas vendedoras, "correios humanos" de drogas ou transportadoras de drogas (AMADOR, 2016, p. 11; GIACOMELLO, 2013).

Apesar do caráter transgressivo da atividade na qual as participantes estiveram envolvidas, suas experiências passadas como criminosas foram marcadas por uma constante submissão aos homens na atividade. Apesar das participantes terem se sentido superiores a outras mulheres que não tiveram envolvimento com o tráfico de drogas, o poder afirmado foi frequentemente experimentado dentro dos limites de gênero que caracterizam as experiências de mulheres 'normais' da favela. Como claramente afirmado por uma das participantes, às mulheres é permitido somente um 'certo poder' no tráfico de drogas (BARCINSCK, 2009, p. 1852).

$\mathrm{Na}$ dinâmica dessas atividades, as mulheres são facilmente substituídas, incorrendo em detenções inócuas à diminuição do tráfico de drogas (AMADOR, 2016, p. 11; CELS, 2015), mostrando que:

A rapinagem sobre o feminino se manifesta tanto sob as formas de destruição corporal sem precedentes, como sob as formas de tráfico e comercialização de tudo o que estes corpos podem oferecer, até ao seu limite. A ocupação depredadora dos corpos femininos ou feminizados se pratica como nunca até aqui e, nesta etapa apocalíptica da humanidade, espolia até deixar somente restos. Pensar aquela situação me levou a perceber que a crueldade e o desamparo das mulheres aumentam à medida que a modernidade e o mercado se expandem e anexam novas regiões (SEGATO, 2012, p. 108).

Esse cenário deve ser compreendido a partir de uma trajetória histórica mais profunda na América Latina, remetendo à eleição dos homens como interlocutores privilegiados para/pelos interesses da colonização e, atualmente, dos negócios e empresas $^{5}$. A carga histórica da colonização traz consigo uma perda radical do poder

\footnotetext{
5 As discussões sobre se o gênero é ou não categoria colonial proliferaram a partir da importante intervenção de Lugones, com várias autoras apresentando argumentos a favor e contra a existência dessa
} 
das mulheres (GAUTIER, 2005, p. 718) e, ao mesmo tempo, a "domesticação" delas e sua maior distância e sujeição para facilitar a empreitada colonial (SEGATO, 2012, p. 120).

Essa dominação produziu e produz vítimas (de muitas e variadas maneiras), através da violência que é interpretada como um ato inevitável e com o sentido quaseritual de sacrifício. $\mathrm{O}$ "herói civilizador reveste a suas próprias vítimas da condição de serem holocaustos de um sacrifício salvador (o índio colonizado, o escravo africano, $\underline{\text { a }}$ mulher, a destruição ecológica)" (DUSSEL, 2000, p. 49, grifo nosso).

Há assim, uma exterioridade colonial moderna, entendida como exterioridade da racionalidade científica, exterioridade administradora, exterioridade expurgadora do outro e da diferença, que levam essa característica de domínio do corpo e da atividade feminina, desde um olhar colonizador (QUIJANO, 1992; MIGNOLO, 2000 e 2003). Em um contexto mais amplo:

Assim, a modernidade é um discurso que define a sua interioridade ao criar a diferença a ser marginalizada e eliminada. A retórica da modernidade tem um vocabulário abundante para marcar a diferença, para criar exterioridade espacial e temporalmente: pagãos, bárbaros, primitivos, mulheres, gays, lésbicas, negros, índios, subdesenvolvidos, as economias emergentes, comunistas, terroristas, amarelos, etc. Todos estes serão incorporados na modernidade ou deixado de fora quando necessário. (MIGNOLO, 2012, p. 26).

É nessa perspectiva histórica, que as mulheres latino-americanas estão inseridas na parte subalterna e mais arriscada da cadeia do crime. São corpos, objetos, facilmente substituídos com o encarceramento, na tradução da "rapinagem sobre o feminino" que manifesta formas de destruição corporal, social e familiar sem precedentes.

Por outro lado, as mulheres começam a ascender a posições mais importantes, como gerentes e donas de boca de fumo e redes de distribuição. Tal hipótese não nega que o gênero seja um elemento substancial nas limitações impostas a estas mulheres na atividade do tráfico. Porém, as limitações não estão se demonstrando suficientes para inibir a participação feminina no tráfico. Ao contrário, as mulheres estão apresentando um envolvimento cada vez maior com a atividade e algumas delas, inclusive, alcançam hierarquias até pouco tempo exclusiva aos homens. Tal mudança já é bastante 
perceptível em outros países, como no México, em que as mulheres ocupam postos importantes nos cartéis (HELPES, 2014, p. 59).

O caso do México assume contornos próprios e traz um contraste importante com a participação da mulher no tráfico brasileiro. Exemplo disso é o cartel mexicano “Los Zetas", que possui uma seção feminina, denominada "Las Panteras", dirigida e composta por mulheres. Assim, "la nueva mujer del narco ya no es tan sólo la esposa que comprende en todo al marido, la madre que cuida a los hijos de los capos". A nova mulher do narcotráfico "ya no está tampoco exenta de las venganzas de grupos contrarios. Ahora se involucra activamente en todo tipo de actividades delictivas: la confección de droga, las finanzas o los negocios para el blanqueo de dinero" (GUZMÁN, 2013, p. 138).

Campbell (2008), em análise etnográfica na fronteira do México com os Estados Unidos identificou mulheres que acessam altos postos ("high-level female drug smuggler"), enquanto outras apenas chegam a médios e baixos postos dentro das redes criminosas. A vitimização das mulheres que participam dessas redes é frequente, especialmente nos "níveis" médio e baixo, enquanto que o alto posto é o único que realmente permite alguma forma de empoderamento, na conclusão do autor. Esses estudos caminham no sentido de concluir sobre a manutenção dos padrões de gênero que definem as relações dentro das redes de atividade ilícita. No caso mexicano, a violência contra a mulher se mantém independentemente do nível que ela tenha alcançado na organização, embora em alguns casos específicos seja possível adquirir uma posição de maior comando. O padrão patriarcal das relações vigora, ainda que a mulher ocupe o patamar mais alto da organização. (CAMPBELL, 2008; SOUZA, 2013).

No Brasil, tomando por referência também uma região da fronteira, o lugar social da mulher é marcado pela atuação de indígenas e não indígenas, para o chamado "tráfico formiguinha" (travessia da fronteira com quantidades muito pequenas de droga por vez). Essa é uma das principais causas do aprisionamento e um problema que preocupa autoridades policiais pela vulnerabilidade das pessoas exploradas nessas ações (MINISTÉRIO DA JUSTIÇA, 2013; SOUZA, 2013).

A confluência dos estudos no Brasil e México vem confirmando o quadro mais geral da América Latina, em que os fenômenos do narcotráfico, violência de gênero, migração e feminicídio andam juntos e de forma inter-relacionada historicamente, 
tornando indispensáveis sua análise conjunta para a formulação de políticas públicas eficientes.

\section{CONSIDERAÇÕES FINAIS}

A grande maioria das mulheres presas por delitos de drogas, na América Latina, especialmente no Brasil e México, encontra-se nessa situação por consequência direta ou indireta de uma discriminação multifacetada e transversal à história da região, agravada pela privação de direitos básicos (SOUZA, 2013; LIMSIRA, 2011). Não obstante as diferenças regionais, o resultado é generalizado na América Latina. Entre 2006 e 2011, a população carcerária feminina na América Latina quase dobrou, passando de 40 mil para mais de 74 mil prisioneiras. A grande maioria das mulheres em situação de cárcere estão na prisão por crimes relacionados às drogas, representando percentagens altas, como de $75 \%$ no Equador, de 30 a $60 \%$ no México, 64\% na Costa Rica, 60\% no Brasil e 70\% na Argentina (ADORNO, 2008; AMADOR, 2016; GIACOMELLO, 2013).

Apesar desse variado e enorme contingente, o lugar social das mulheres apresenta na América Latina traços similares. Assim, a busca de drogas serve não apenas para o consumo, mas para participação nas atividades de produção, distribuição, fornecimento e venda de drogas. As condutas se relacionam à exclusão social, à pobreza e à violência de gênero, fazendo com que a maioria das mulheres não tenham, de fato, a liberdade de decidir autonomamente sobre suas vidas pessoais e profissionais. Grande parte possui pouca ou nenhuma instrução educacional e, ainda assim, são responsáveis pelo sustento de seus dependentes (crianças, jovens, pessoas idosas e parentes deficientes). Predomina o perfil de "mães solteiras" e de atividades criminosas como alternativa não apenas de sustento socioeconômico e ganho de renda, mas também de conquista, respeito e empoderamento sociocultural em suas famílias e comunidades. Linhas gerais, estão envolvidas em tarefas de pouca importância, mas de alto risco, voltadas para delitos não violentos de micro-tráfico e/ou transporte de drogas.

As nuances regionais exibem dinâmicas de lugares sociais em transformação. No Brasil, as atividades que envolvem o cultivo, produção e distribuição de drogas colocam a maioria das mulheres latino-americanas no nível mais baixo da cadeia do crime organizado, seja como pequenas vendedoras, "correios humanos" de drogas ou transportadoras de drogas. Diferente disso, no México, as mulheres vem galgando o 
comando da criminalidade organizada e assumindo postos de destaque no tráfico de drogas internacional. Não obstante, os estudos mais recentes confirmam que a mulher no mundo da criminalidade (em especial do tráfico de drogas) assume os trabalhos de maior risco e menor remuneração e poder, em uma estrutura de divisão do trabalho pautada sobre o gênero.

Por fim, a resposta do Estado tem sido ineficiente e estigmatizante, limitandose na grande maioria a políticas públicas de enfoque punitivo e repressivo. As políticas atuais não conseguiram reduzir o tamanho do mercado de drogas e as violações dos direitos humanos contra as amulheres se multiplicaram. Foram exacerbados a violência e os problemas de saúde e de exclusão social. Verificou-se o aumento do uso problemático de drogas, a expansão do alcance e do poder de organizações criminosas, (AMADOR, 2016, p. 11; CELS, 2015), enquanto as instituições estatais vêm assistindo à desorganização dos sistemas de justiça penal.

\section{REFERÊNCIAS BIBLIOGRÁFICAS}

ADORnO, S. Políticas Públicas de Segurança e Justiça Penal. Cadernos Adanauer IX. Segurança Pública. Fundação Konrad Adanauer. P. 9-28. 2008.

ADORNO, S. e CARDIA, N. Núcleo temático: Violência - Nota de apresentação. In: Revista Ciência e Cultura. SBPC - Sociedade Brasileira para o Progresso da Ciência, São Paulo, Ano 54, n. 1, julho de 2002, p. 20-21.

AMADOR, G; AMIGHETTI, D; BARTLEY-MATTHEWS, J; BLAS, I; CAICEDO, L.C; CORTÉS, E; CHAPARRO, N; CHAPARRO, S; CRUZ, L.F; DAUFEMBACK, V; GIACOMELLO, C; LUTZ, L; MOLINA, Z; NOUGIER, M; OLIVEIRA, G; PECOVA, A; PIERIS, N; POL, L; QUINTANILLA D; RUEDA, A.M.; SCHAFFER, A; SESTOKAS, L; SOTOMAYOR, M.C.M; UPRIMNY, R; ACEVEDO, V.V; YOUNGERS, C; BOITEUX, Luciana. Women, Drug Policies, and Incarceration: a guide for public reform in Latin America. Relatório de pesquisa. Coord.: Coletta A. Youngers, Nischa Pieris, Marie Nougier e Sergio Chaparro. Grupo de Trabalho sobre Mulheres, Políticas de Drogas e Encarceramento. Open Society Foundations e Fundación Libra. 50p. 2016.

BARCINSK, M. Centralidade de gênero no processo de construção da identidade de mulheres envolvidas na rede do tráfico de drogas. Ciência e Saúde Coletiva. 2009. 
BERGERON, H. Sociologia da droga. Aparecida: Ideias \& Letras. 2012.

BOITEUX, L; CHERNICHARO, L; BARRETO, A. L. Mujeres y encarcelamiento por delitos de drogas. Colectivo de Estudios Drogas y Derecho. Coord.: Catalina Pérez Correa. Edición y Diseño: Ariana Ángeles García y Karen Silva Mora. RJ: CEDD, PPGD/UFRJ e LADIH/UFRJ. 12p. 2015.

CAMPBELL, Howard. Female drug smugglers on the US-Mexico border: gender, crime, and empowerment. Anthropological Quarterly, vol. 81, n. 1, p.233-267, 2008.

CASTRO, L. F. P.; IGREJA, R. F. A. M. L. Estrangeirização de Terras na Perspectiva das Formas de Colonialidade no Agro Latino-Americano. Revista de Estudos e Pesquisas sobre as Américas, v. 11, p. 204-219, 2017. No prelo.

CELS. Centro de Estudios Legales y Sociales - CELS. El impacto de las políticas de drogas en los derechos humanos: la experiencia del continente americano. Coordinación y edición: Luciana Pol, Ximena Tordini, Paula Litvachky y Gabriela Kletzel. Colaboración de Edurne Cárdenas. 69p. 2015. Disponível em: http://www.cels.org.ar/common/Drogas web hojas.simples.pdf. Acesso em 14.05.17.

COSTA, C.L. Feminismos descoloniais para além do humano. Rev. Estud. Fem., Florianópolis , v. 22, n. 3, p. 929-934, Dec. 2014.

COSTA RICA. Defensoria Pública da Costa Rica. Estudio de la Defensa Pública de Costa Rica sobre el perfil de la población femenina privada de libertad por introducir drogas a los centros penales. Defensoria Pública; abril de 2012.

DUSSEL, E. Europa, modernidad y eurocentrismo, em LANDER, Edgardo (coord.). La colonialidad del saber: eurocentrismo y ciencias sociales, perspectivas latinoamericanas. Buenos Aires: Clacso. 2000.

ENLOE, C. Banana, Beaches and Bases: Making Sense of International Politics. Berkeley: University of California Press. 1990.

GAUTIER, A. Mujeres y colonialismo. In Marc Ferro (dir.), El libro negro del colonialismo. Siglos XVI al XXI: Del exterminio al arrepentimiento. Madrid: La esfera de los libros. 2005.

GIACOMELLO, C. Género, drogas y prisión. México. Tirant lo Blanch. 2013. Mujeres, delitos de drogas y sistemas penitenciarios en América Latina. International Drug Policy Consortium. 2013. Disponível em: https://www.unodc.org/documents/congress//background- 
information/NGO/IDPC/IDPC-Briefing-Paper Women-in-Latin-

America_SPANISH.pdf. Acesso em 14.05.17.

GÓMEZ, A. S. Las jefas del narco: El ascenso de las mujeres en el crimen organizado. Grijalbo. 2013.

GROSFOGUEL, R. Para descolonizar os estudos de economia política e os estudos póscoloniais: transmodernidade, pensamento de fronteira e colonialidade global. Revista Crítica de Ciências Sociais, n. 80, p. 115-147, 2008.

GUZMÁN, J. C. Las tres jefas. In: A. S. Gómez, Las jefas del narco: El ascenso de las mujeres en el crime organizado. Pp. 125-138. Grijalbo. 2013.

HELPES, S.S. Vidas em jogo: um estudo sobre mulheres envolvidas com o tráfico de drogas. 2014. 195 p. Dissertação (mestrado acadêmico) - Universidade Federal de Juiz de Fora, Instituto de Ciências Humanas. Programa de Pós-Graduação em Ciências Sociais, 2014.

HERNÁNDEZ, A.P. Legislación de drogas y población carcelaria en México. Metaal, Pien y Youngers, Coletta, Sistemas sobrecargados. Leyes de drogas y cárceles en América Latina. Washington DC-Ámsterdam: Transnational Institute-Washington Office on Latin America. 2011.

INDEPAZ. Instituto de Estudios para el Desarrollo y la Paz (Indepaz). Vicios penales: cultivadores de coca, amapola y marihuana, en la hora de su despenalización. Observatório Colombiano de Cultivadores e Cultivos Declarados Ilícitos. Julho de 2015. Disponível em: http://www.indepaz. org.co/wp-content/uploads/2015/08/ViciosPenales-ANEXOS-ultima-version-30-julio.pdf. Acesso em 14.05.17.

INPEC. Instituto Nacional Penitenciario y Carcelario. Estadísticas a diciembre de 2014. Disponível em: http://www.inpec.gov.co/portal/page/portal. Acesso em 14.05.17. Kensy, J; Stengal, C; NOUGIER, M; BIRGIN, R. Drug Policy and Women: Addressing the Negative Consequences of Harmful Drug Control. November 30, 2012. International Drug Policy Consortium, 2012. Disponível em: SSRN: https://ssrn.com/abstract=2186004 or http://dx.doi.org/10.2139/ssrn.2186004.

Acesso em 14.05.17.

LIMSIRA, P. The United Nations Rules for the Treatment of Women Prisoners and Non-Custodial Measures for Women Offenders (Bangkok Rules). JE Asia \& Int'l L., v. 4, p. 241, 2011. 
METAAL, P; YOUNGERS, C. Sistemas sobrecargados: leyes de drogas y cárceles en América Latina. WOLA y TNI. 2010. Disponível em: http://www.wola.org/sites/default/files/downloadable/Drug\%20Policy/2011/Spanish/sist emas sobrecargados web2.pd. Acesso em 14.05.17.

MIGNOLO, W. Decolonizing Western Epistemology/Building Decolonial Epistemologies. In: ISASI-DÍAZ, Ada María; MENDIETA, Eduardo (Eds.). Decolonizing Epistemologies: Latina/o Theology and Philosophy. New York: Fordham University Press, p. 19-43, 2012a.

MINISTÉRIO DA JUSTIÇA. Pesquisa Enafron: Diagnóstico sobre tráfico de pessoas nas áreas de fronteira. 2013. Disponível em: http://www.justica.gov.br/suaprotecao/trafico-de-pessoas/publicacoes/anexos-

pesquisas/pesquisa nafron 202x266mm 1710 19h00 web.pdf. Acesso em 15.05.17.

MISSE, M. O Movimento: A constituição e reprodução das redes do mercado informal ilegal de drogas a varejo no Rio de Janeiro e seus efeitos de violência. Drogas e PósModernidade. 2013.

.Coloniality of Power, Ethnocentrism, and Latin America, NEPANTLA, $1(3), 533-580.2000$.

PIERIS, N. Mujeres y drogas en las Américas: un diagnostico de política en construcción. CIM/OEA, 2014. Disponível em http://www.oas.org/en/cim/docs/WomenDrugsAmericas-ES.pdf. Acesso em 14.05.17. QUIJANO, A. Colonialidade do poder, eurocentrismo e América Latina. Disponível em: http://bibliotecavirtual. clacso. org. ar/ar/libros/lander/pt. Acesso em 15.05.17.

RATTON, J. L., Galvão, C., e Andrade. Crime e Gênero: controvérsias teóricas e empíricas sobre a agência feminina. Curitiba. 2011.

RESTREPO, E.; ROJAS, A. Inflexión decolonial: Fuentes, conceptos y cuestionamientos. Popayán, Colombia: Editorial Universidad del Cauca, 2010.

La colonialidad del poder y la experiencia cultural latinoamericana, in Roberto Briceño-León; Heinz R. Sonntag (orgs.), Pueblo, época y desarrollo: la sociología de América Latina. Caracas: Nueva Sociedad, 139-155. 1998.

. “Raza', 'Etnia' y 'Nación' en Mariátegui: Cuestiones Abiertas”, in Roland Morgues (org.), José Carlos Mariátgui y Europa: El Otro Aspecto del Descubrimiento. Lima, Perú: Empresa Editora Amauta S.A., 167-187. 1993. 
SEGATO, R.L. Gênero e colonialidade: em busca de chaves de leitura e de um vocabulário estratégico descolonial. E-cadernos CES, n. 18, p. 106-131, 2012.

SOUZA, L.L. As consequências do discurso punitivo contra as mulheres" mulas" do tráfico internacional de drogas: ideias para a reformulação da política de enfrentamento às drogas no Brasil. Parecer elaborado no âmbito do Projeto Justiça Criminal do Instituto Terra, Trabalho e Cidadania. ITTC: São Paulo, 2013.

SPIVAK, G. In Other Worlds: Essays in Cultural Politics. New York: Routledge, Kegan and Paul. 1988.

WALMSLEY, R. World Female Imprisonment List. Institute for Criminal Policy Research at Birbeck University of London. London. Outubro de 2015, p. 2, 13. 